\title{
In vitro Anti-Toxoplasma gondii Activity of Root Extract/Fractions of Eurycoma longifolia Jack
}

\author{
Nowroji Kavitha ${ }^{1 \dagger}$, Rahmah Noordin $^{1 \dagger},{\text { Kit-Lam } \text { Chan }^{2 \dagger} \text { and Sreenivasan Sasidharan }}^{1 *+}$
}

\begin{abstract}
Background: Toxoplasma gondii infection causes toxoplasmosis, an infectious disease with worldwide prevalence. The limited efficiency of drugs against this infection, their side effects and the potential appearance of resistant strains make the search of novel drugs an essential need. We examined Eurycoma longifolia root extract and fractions as potential sources of new compounds with high activity and low toxicity. The main goal of this study was to investigate the anti-T. gondii activity of crude extract (TACME) and four fractions (TAF 273, TAF 355, TAF 191 and TAF 401) from E. longifolia, with clindamycin as the positive control.
\end{abstract}

Methods: In vitro toxoplasmacidal evaluation was performed using Vero cells as host for T. gondii. Light microscopy technique was used to study in situ antiparasitic activity.

Results: Significant anti-T. gondii activity was observed with clindamycin (EC50 = $0.016 \mu \mathrm{g} / \mathrm{ml}$ ), follow by TAF 355 $(E C 50=0.369 \mu \mathrm{g} / \mathrm{ml})$ and TAF $401(E C 50=0.882 \mu \mathrm{g} / \mathrm{ml})$. Light microscopy revealed that most Vero cells were infected after $3 \mathrm{~h}$ of exposure to T. gondii. After $36 \mathrm{~h}$ of exposure to the E. longifolia fraction, the host Vero cells showed no visible intracellular parasite and no remarkable morphological changes.

Conclusions: Our study demonstrated that TAF 355 and TAF401 fractions may be the sources of new anti-T. gondii compounds.

Keywords: Toxoplasma gondii, Eurycoma longifolia, Antiparasite, Toxoplasmosis, Toxoplamacidal activity

\section{Background}

Parasitic diseases still cause a major challenge to human well-being, particularly in poor populations living in tropical and subtropical climates with low-income economies [1]. Some conventional drugs are unaffordable for them and health facilities are also inaccessible. One of the common infections in tropical and subtropical climates is toxoplasmosis caused by Toxoplasma gondii. It is one of the most widespread protozoan parasites, chronically infecting approximately $30 \%$ of the global human population [2]. T. gondii causes severe neurological deficits in immunosuppressed patients (such as those with AIDS) and lymphadenopathy in healthy adults. It can cross the placenta (generally in women with no or low antibody levels) and cause congenital infections characterized by

\footnotetext{
* Correspondence: srisasidharan@yahoo.com

${ }^{\dagger}$ Equal contributors

'Institute for Research in Molecular Medicine (INFORMM), Universiti Sains Malaysia, 11800 USM, Pulau Pinang, Malaysia

Full list of author information is available at the end of the article
}

intra-cerebral calcifications, chorioretinitis, hydrocephaly or microcephaly, and convulsions [3].

Anti-T. gondii agents consisting of a combination of pyrimethamine and sulphonamides, especially sulphadiazine, are still most frequently used, and they inhibit dihydrofolate reductase, a key enzyme in the synthesis of purines $[4,5]$. Other alternative drugs include clindamycin, atovaquone and spiramycin. The treatment of $T$. gondii infections, in general, accentuates the problem of the limited effectiveness of the available anti-parasitic agents, their side effects and the potential appearance of resistant strains. Other options for the toxoplasmosis treatment are desirable, thus the search for new anti-parasitic agents is needed.

The need for fundamental research [6] on anti-T. gondii agents leads our study. On the other hand, the choice of using $E$. longifolia as source was based on previous reports activity against Plasmodium parasite. Like T. gondii, Plasmodium is an apicomplexan intracellular protozoa,

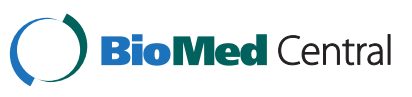


therefore E. longifolia can also be a potential source of anti- $T$. gondii agents.

E. longifolia Jack, from the Simaroubaceae family and identified locally as 'Tongkat Ali' or 'Pasakbumi' has been commonly prescribed in traditional medicine as a febrifuge and a remedy for dysentery, glandular swelling and fever $[7,8]$. E. longifolia is found in primary and secondary, evergreen and mixed deciduous forests in Burma, Indochina, Thailand, Malaysia, Sumatra, Borneo and Philippines. It is popularly sought after as a singly or an essential component for the treatment of fevers, aches, sexual insufficiency and also as health supplements. Traditional medicinal users usually take a decoction of the roots in water as a health tonic and anti-stress remedy. Extracts derived from the roots of this plant were also found to demonstrate activity when evaluated with the sarcoma 180 model [9]. Moreover, anti-malarial [10-14] and cytotoxic [15-18] activities were also reported being linked to the presence of quassinoids, squalene derivatives, biphenyl-neolignans, tirucallane-type triterpenes, canthine-6-one and carboline alkaloids. Specially, three quassinoids, eurycomanone, its $13 \alpha(21)$-epoxy and 13 , 21-dihydro analogues were identify as having greater anti-plasmodial activity [19].

\section{Methods}

\section{Plant material}

The roots of E. longifolia Jack were identified and purchased in Perak, Malaysia by a pharmaceutical company, Hovid Berhad, in Ipoh. A voucher specimen (No. 785-117) was deposited in Penang Botanical Garden, Penang, Malaysia.

\section{Extraction and isolation}

The air-dried powdered roots of E. longifolia was extracted with $6 \times 4 \mathrm{~L}$ of $95 \%$ methanol for 6 days at $60^{\circ} \mathrm{C}$. The combined methanol extract was then evaporated to dryness to yield a dark brown residue. Subsequently, this dark brown residue was chromatographed on a resin column with several alcohol/water mixtures to yield four fractions (Fr 1-4) such as alcohols layers, water layer and residue layers. The four fractions were concentrated under vacuum and were resuspended in water and then partitioned successively with saturated $n$-butanol to yield several sub-fractions. Successive column chromatography using silica gel and centrifugal thin-layer chromatography of the sub-fractions with various $\mathrm{CHCl}_{3}$-methanol mixtures yielded the desired four active sub-fractions fractions (TAF 273, TAF 355, TAF 191 and TAF 401). The fractions that contained TAF 273, TAF 355, TAF 191 and TAF 401 were identified by TLC comparison. One methanol extracts (TACME) and four fractions (TAF 273, TAF 355, TAF 191 and TAF 401) were used in this study. The RPMI-1640 medium was used as the solvent for preparation of different dilutions of the plant extracts.

\section{Toxoplasma gondii strain}

The experimental procedures relating to the animals were authorized by Universiti Sains Malaysia Ethical committee (USM/ PPSF50(003)JLD2) before starting the study and were conducted under the internationally accepted principles for laboratory animal use and care. Tachyzoites from the virulent $\mathrm{RH}$ strain of $T$. gondii were maintained by intraperitoneal passages in Swiss albino mice and collected in phosphate-buffered saline (PBS), $\mathrm{pH} 7.2$, at 3-4 day intervals. The ascites fluid obtained from infected mice was centrifuged at $200 \times g$ for $10 \mathrm{~min}$ at room temperature to remove host cells and debris. The supernatant, which contained the parasites, was collected and centrifuged at $1000 \times g$ for 10 min. The pellet was washed with PBS, pH 7.2 and then in RPMI medium without foetal bovine serum (FBS). The parasites were used within 30-40 min of their removal from the mice peritoneal cavity and the viability was evaluated using the trypan blue dyeexclusion test.

\section{Host cells}

The results of our previous study indicated that E. longifolia fractions did not have a significant effect on Vero cell growth, and E. longifolia fractions can be used safely for the anti-Toxoplasma assay [20]. The cell line was initiated from kidney of a normal adult African green monkey on March 27th, 1962, by Yasummura and Kawakita at the Chiba University, Japan (American Public Health Association, 1992). Vero cells were maintained in RPMI-1640 medium supplemented with $10 \% \mathrm{FBS}$, glutamine ( $2 \mathrm{raM})$, penicillin $(100$ units $/ \mathrm{ml})$ and streptomycin $(100 \mu \mathrm{g} / \mathrm{ml})$. The cells were cultured at $37^{\circ} \mathrm{C}$ in a humidified $5 \% \mathrm{CO}_{2}$ incubator.

\section{Assay of toxoplasmacidal activity}

In vitro toxoplasmicidal studies were carried out using the method described by Cover and Gutteridge [21]. Briefly, $45 \mu \mathrm{l}$ of tachyzoites suspension containing $10^{6}$ cells/ml were incubated, with $5 \mathrm{~mL}$ of each fractions/ clindamycin (dissolved in DMSO $[1 \% \mathrm{w} / \mathrm{v}]$ at final concentration of $1.56-100 \mu \mathrm{g} / \mathrm{ml}$ ) [22] at $37^{\circ} \mathrm{C}$ in 96 wells micro plates. Tachyzoites vitality was determined under an inverted microscope with the trypan blue dye exclusion test after $24 \mathrm{~h}$ of incubation in $10 \% \mathrm{CO}_{2}$ chamber. The results were expressed as \% mortality. Clindamycin (Sigma, USA), a drug that has been used in human and animal anti-T. gondii therapy was used as the positive control [23]. The extract/fractions were assayed in triplicate at each concentration.

\section{In vitro infection and effectors}

Vero cells were harvested during exponential growth (day 2) and cultured in 96-well plates (ca. $6 \times 10^{4}$ cells $\left./ \mathrm{ml}\right)$. Then, $3 \times 10^{5}$ parasites/ml were added to each well (parasite: cell 
Table 1 In vitro anti-T. gondii RH strain activity and selectivity of $E$. longifolia fractions and clindamycin

\begin{tabular}{lcc}
\hline Tested drugs name & $\mathrm{EC}_{\mathbf{5 0}}(\boldsymbol{\mu} \mathbf{g} / \mathbf{m l})$ & Selectivity $^{\mathbf{a}}$ \\
\hline Fractions TAF 355 & 0.369 & 63.7 \\
Fractions TAF 401 & 0.882 & 17.0 \\
Clindamycin (Positive control) & 0.016 & 656.3 \\
\hline
\end{tabular}

$\mathrm{EC}_{50}$, median effective concentration.

a Ratio of the $\mathrm{EC}_{50}$ value for Vero cells to the EC50 value for Toxoplasma gondii tachyzoites. The EC50 value for Vero cells was used from our previously published data (TAF $35=23.50 \mu \mathrm{g} / \mathrm{ml}$, TAF $401=15.00 \mu \mathrm{g} / \mathrm{ml}$ and Clindamycin $=10.5 \mu \mathrm{g} / \mathrm{ml}$ ) [20].

ratio $=5: 1$, final volume $200 \mu \mathrm{l}$ ) [24]. Six hours after inoculation, the infected cells were washed twice with RPMI 1640 medium without FBS to remove any non-adherent parasites. After 18 h incubation, RPMI 1640 medium supplemented with $2 \%$ FBS was added to each well along with different concentrations of the fractions/ clindamycin (at final concentration of $1.56-100 \mu \mathrm{g} / \mathrm{ml}$ ) [22]. After $24 \mathrm{~h}$ of treatment, anti- $T$. gondii activity and cytotoxicity of the extracts were examined using an MTS (3-(4,5-dimethylthiazol-2-yl)-5-(3carboxymethoxyphenyl)-2-(4-sulfophenyl)-2 H-tetrazolium, inner salt) (Promega, Madison, WI) assay [25]. The assay was conducted in 96-well plates and assayed using a microplate reader (Spectra Max Gemini XG, parameters chosen in SOFT max pro 4.0; Molecular Devices, Sunnyvale, CA) using a wavelength of $490 \mathrm{~nm}$. Fraction TAF 355 and TAF 401 which showed the best toxoplasmacidal activity were assayed in triplicate at each concentration in this study. All data points represent the mean of three independent experiments. The median effective concentration $\left(\mathrm{EC}_{50}\right)$ value refers to the concentration of the fractions/ clindamycin necessary to inhibit $50 \%$ of the control values. Selectivity refers to the mean of the $\mathrm{EC}_{50}$ value for Vero cells relative to the mean of the $\mathrm{EC}_{50}$ value of the $T$. gondii [26].

\section{Light microscope observation of the tachyzoites in cell lines}

Cell line was cultured on a glass cover slip in a $35 \mathrm{~mm}$ cell culture dish until confluent, and then infected with $1 \times 10^{4}$ tachyzoites/dish. After incubation for $4 \mathrm{~h}$, the monolayers were washed with Hanks balanced salt solution (HBSS; Gibco Inc., USA) and the fractions in RPMI medium were added. The glass cover slips were taken from the dishes at $0,1,2,3,4,5,6,8,10,12,24$, or $36 \mathrm{~h}$ after adding the TAF 355, TAF 401, clindamycin and $1 \%$ DMSO (negative control). All the glass cover slips were washed with HBSS and fixed by methanol prior to staining with Giemsa (Sigma Inc., USA). All the prepared samples were observed under oil lens at $1000 \times$ magnification on a light microscope, and the images were captured by using the camera and software [22].

\section{Statistical analysis}

All values are expressed as the mean \pm S.D. of three measurements. Statistical analysis was performed using ANOVA followed by Tukey's Honestly Significant Differences (HSD) using SPSS software. Significance was assumed as $p<0.05$. Probit analysis of mortality data from MTS assay was conducted using SPSS (ver10.0) computer software (SPSS for Windows, SPSS Inc., 1997). The Probit analysis of mortality output was used to calculate the $\mathrm{LC}_{50}$ value.

\section{Results}

\section{Toxoplasmacidal activity}

The results of in vitro anti- $T$. gondii activity against T. gondii RH strain and selectivity are summarised in Table 1 and Figure 1. Toxoplasmacidal activity was found in all the samples tested and mortality was

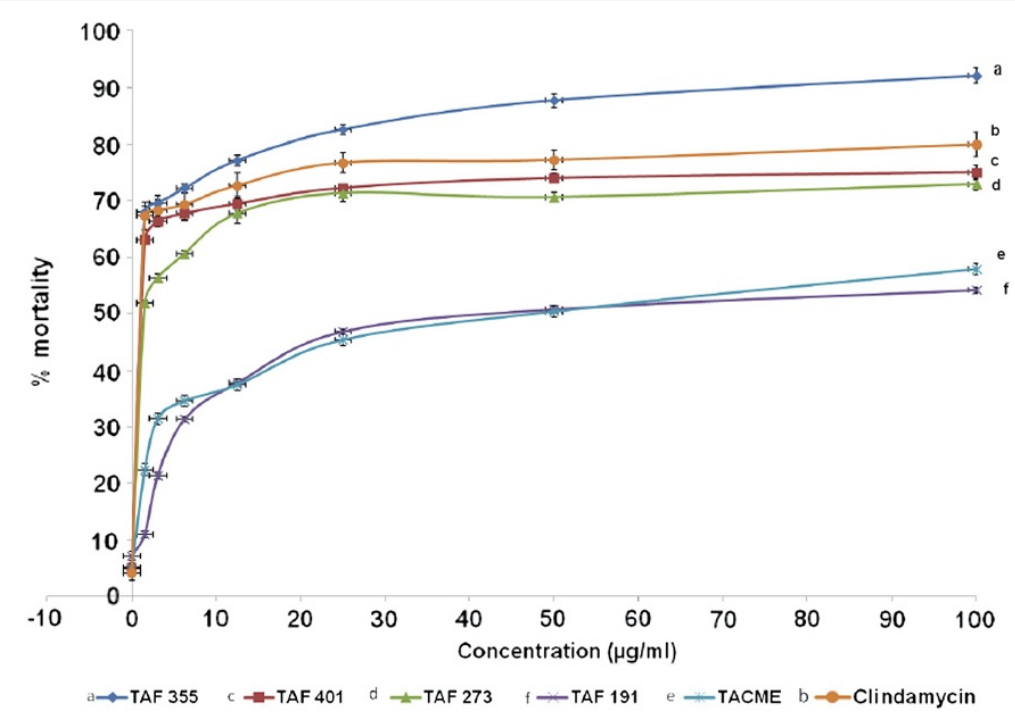

Figure 1 Effects of $E$. longifolia fractions on the proliferation of $T$. gondii tachyzoites. 
observed in the following order $(\mathrm{P}<0.05)$ : TAF $355>$ clindamycin $>$ TAF $401>$ TAF $273>$ TACME $>$ TAF 191 (Figure 1). Clindamycin had high anti- $T$. gondii activity $(\mathrm{EC} 50=0.016 \mu \mathrm{g} / \mathrm{ml}$ and selectivity $=656.3)$ relative to TAF $355($ EC50 $=0.369 \mu \mathrm{g} / \mathrm{ml}$ and selectivity $=63.7)$ and TAF $401 \quad(\mathrm{EC} 50=0.882 \mu \mathrm{g} / \mathrm{ml}$ and selectivity $=17.0)$. Based on these results TAF 355 and TAF 401 were used for further in-vitro anti-Toxoplasma activity evaluation.

\section{In vitro infection and effectors}

Figures 2, 3 and 4 showed the effects of TAF 355, TAF 401 and clindamycin on infected cells with $T$. gondii. At each concentration TAF 355 and TAF 401 inhibited T. gondii tachyzoites in Vero cells in a concentration-dependent manner. Even at low concentrations TAF 355 and TAF 401 dramatically inhibited $T$. gondii tachyzoites in Vero cells. TAF 355 showed the greatest inhibition on $T$. gondii tachyzoites growth in Vero cells with lowest $\mathrm{EC}_{50}$ value $(0.369 \mu \mathrm{g} / \mathrm{ml})$ followed by TAF $401(0.882 \mu \mathrm{g} / \mathrm{ml})$.

\section{Observing the effect of anti-Toxoplasma gondii under microscope}

The observation of the effects of $1 \%$ DMSO, clindamycin, TAF 355 and TAF 401 under light microscope on T. gondii in Vero cells are shown in the Figures 5, 6, 7 and 8 . After infection for $3 \mathrm{~h}$, many parasites were observed inside the Vero cells (Figure 5). Tachyzoites can be seen inside the Vero cells as well as adhered to the glass coverslip in the negative control group treated with $1 \%$ DMSO, even at $36 \mathrm{~h}$. The morphology of Vero cells were changed remarkably in the negative control group with lowest confluence of Vero cells at $36 \mathrm{~h}$. However, when $100 \mu \mathrm{g} / \mathrm{ml}$ clindamycin, TAF 355 and TAF 401 were added (Figure 6, 7 and 8) the number of tachyzoites decreased sharply. Merely $3 \mathrm{~h}$ after adding the drugs or fractions, there were few visible

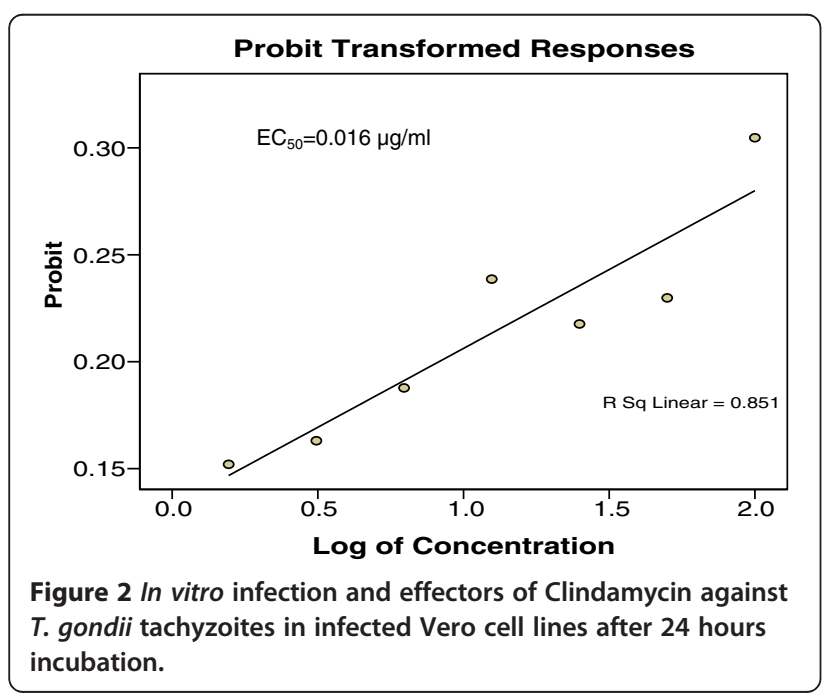

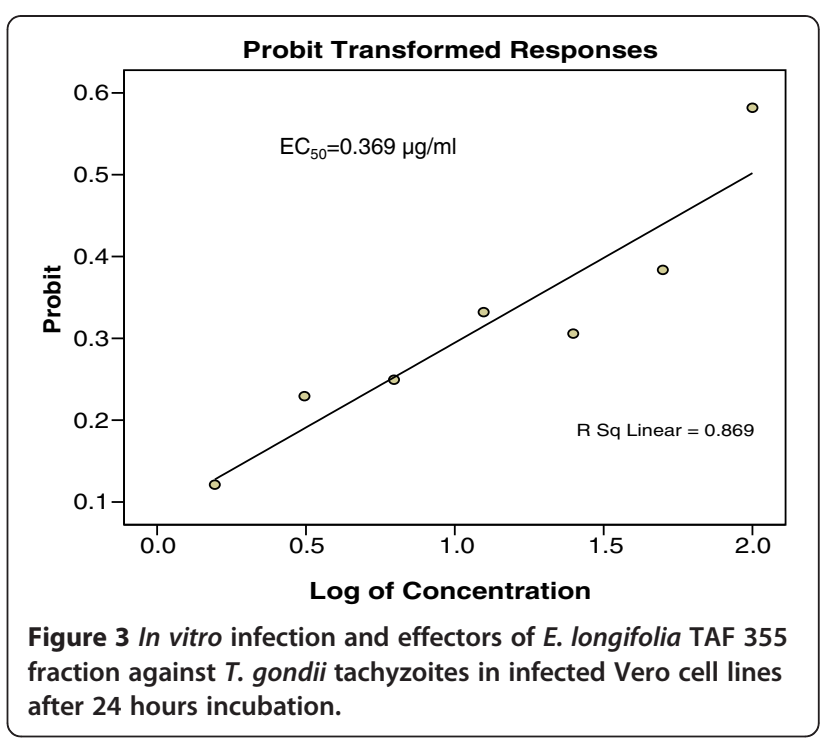

parasites in the infected cells. After $6 \mathrm{~h}, T$. gondii tachyzoites were rarely seen in the infected cells, which continued to grow. Vero cells did not change remarkably after exposure to TAF 355 and TAF 401 for $36 \mathrm{~h}$ compared to the positive control. In addition, the degree of confluence of Vero cells exposed to TAF 355 was highest, followed by TAF 401, and lowest confluence was seen for the cells treated with clindamycin, as expected.

\section{Discussion}

Diseases caused by tropical parasites affect hundreds of millions of people worldwide but have been largely neglected for drug development because they only affect people in poor regions of the world [27]. Hence the development of cheap, reliable and affordable drugs to

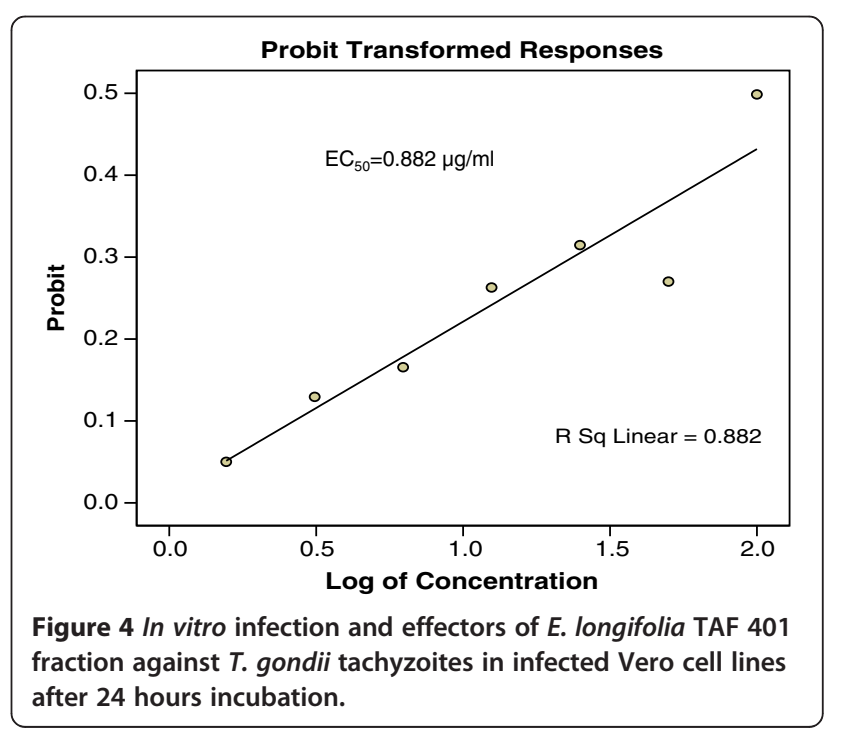




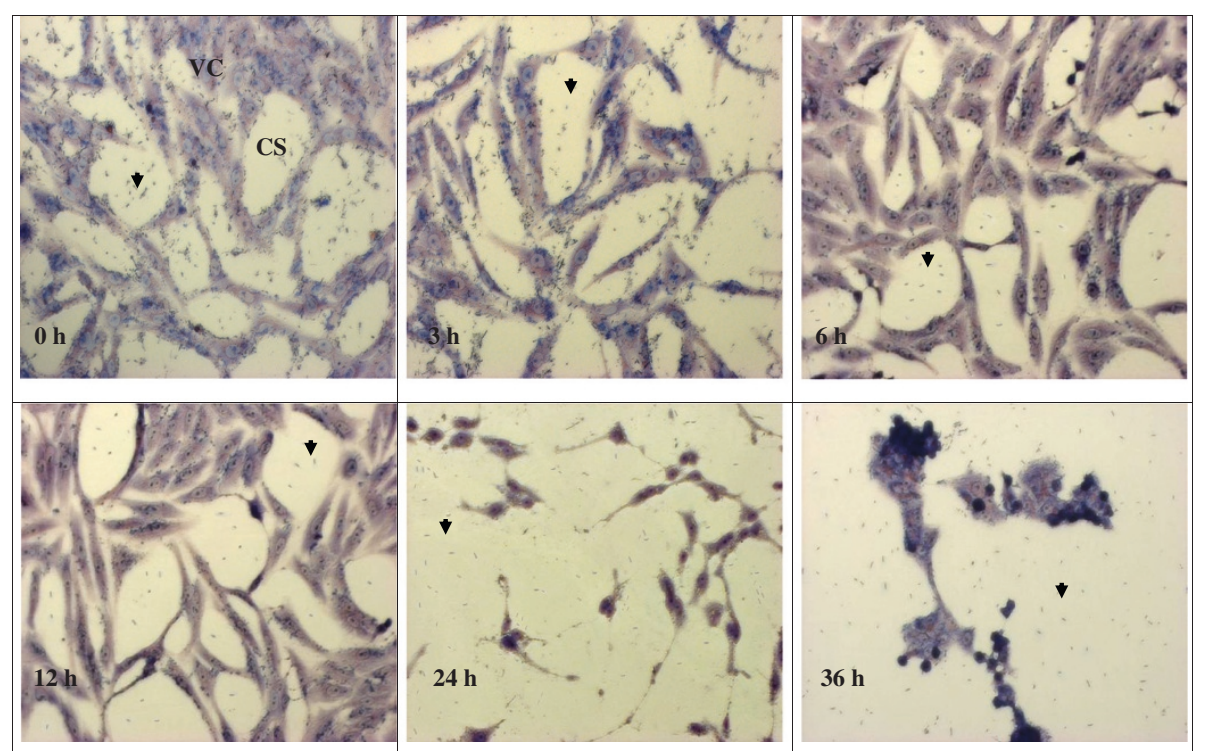

Figure 5 Morphology of Vero cells infected with $T$. gondii with 1\% DMSO (negative control) treatment stained using Giemsa staining. The tachyzoites $(\downarrow)$ can be seen inside the Vero cells (VC), as well as adhered to the glass cover slip (CS).

address this problem is of paramount importance. The discovery of anti-parasitic drugs requires investigation of molecules with the ability to kill parasites but not their hosts. Recently, greater emphasis has been given towards the studies on complementary and alternative medicine that deals with parasitic disease management. Several studies have been conducted on herbs under a multitude of ethno botanical grounds. While the pharmaceutical industry has a long track record of success in developing natural product drugs for the parasitic diseases market, for more than half a century there has also been an active interest in the systematic screening of extracts from medicinal plants and other organisms for their potential anti-parasitic properties. Therefore, the current study was conducted to develop a new anti-Toxoplasma agent from our local medicinal plant E. longifolia.

The anti- $T$. gondii activity of $E$. longifolia has not been reported before. In this study, we found that E. longifolia fractions significantly inhibited $T$. gondii growth, even at low concentrations $(0.369 \mu \mathrm{g} / \mathrm{ml})$. The most potent anti-T. gondii activity was found in TAF 355, which showed an EC50-value of $0.369 \mu \mathrm{g} / \mathrm{ml}$, indicating a good

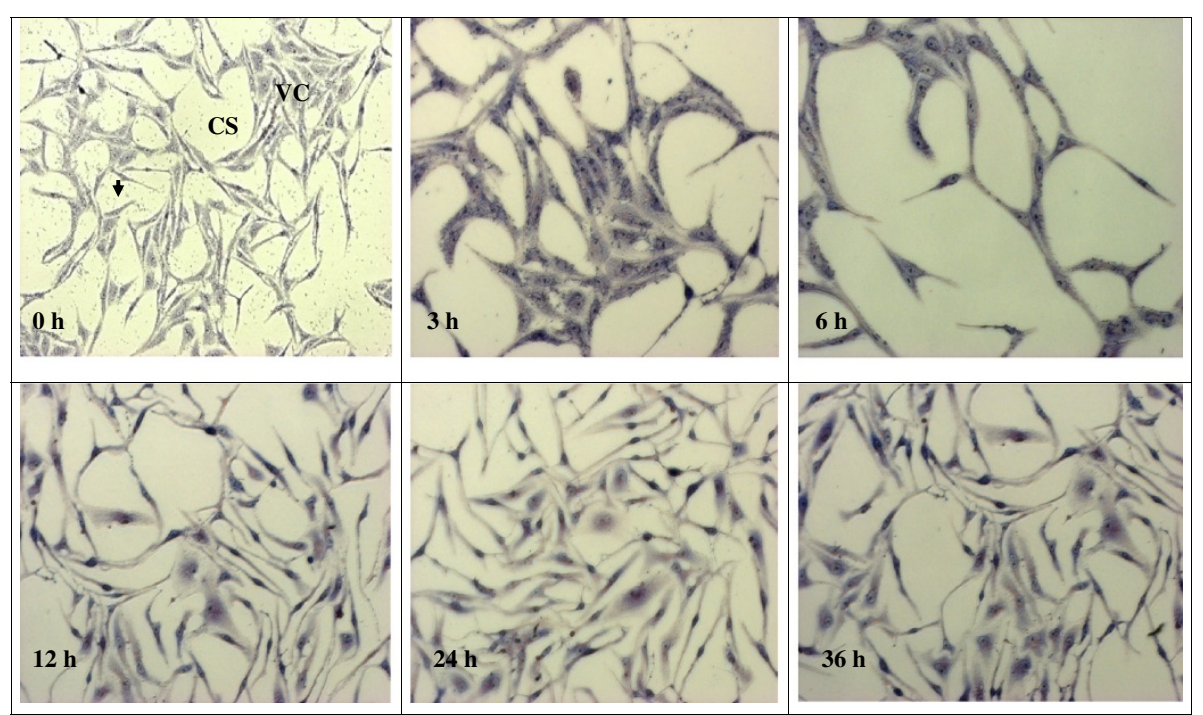

Figure 6 Morphology of Vero cells infected with T. gondii and clindamycin-treatment stained using Giemsa staining. The tachyzoites ( $\downarrow$ ) can be seen inside the Vero cells (VC), as well as adhered to the glass cover slip (CS). 

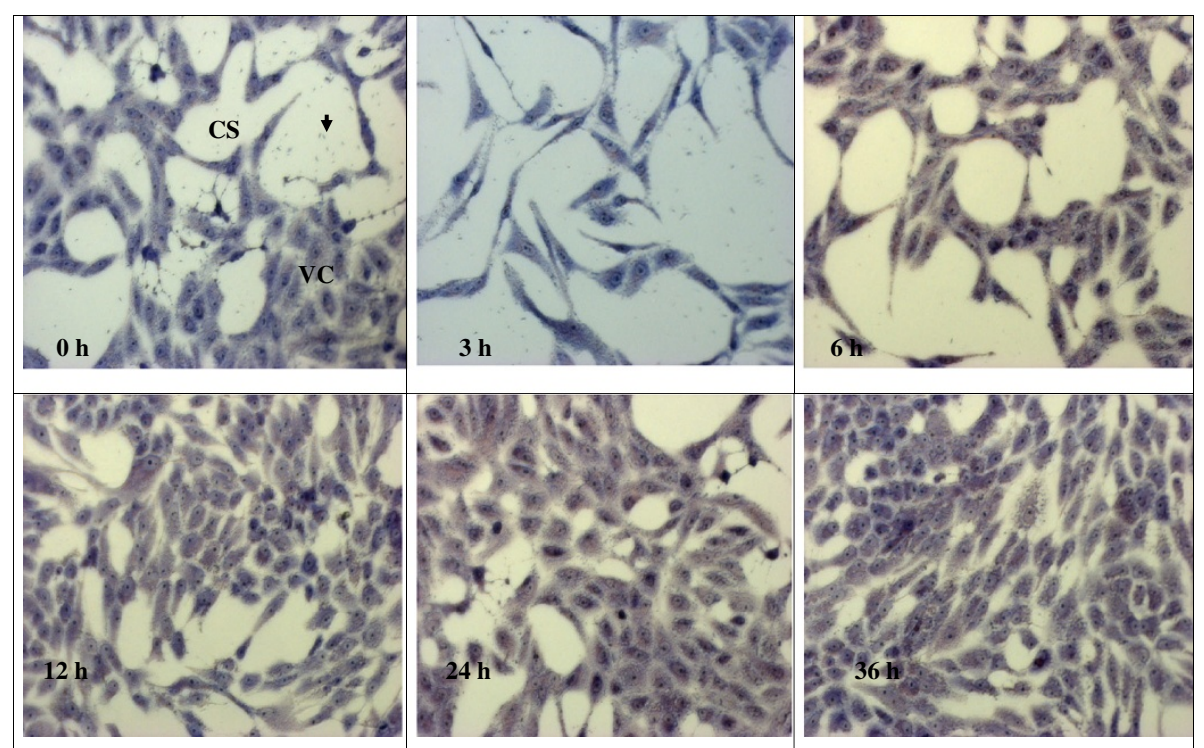

Figure 7 Morphology of Vero cells infected with T. gondii and TAF 355-treatment stained using Giemsa staining. The tachyzoites ( $\downarrow$ ) can be seen inside the Vero cells (VC), as well as adhered to the glass coverslip (CS).

anti-T. gondii activity. In addition, TAF 355 showed high anti- $T$. gondii activity but had no toxicity against the host cells. This finding was proved in our previous study where one extract (TACME) and four fractions (TAF 273, TAF 355, TAF 191 and TAF 401) from E. longifolia root were evaluated for their in vitro cytotoxicity activity against Vero cells. The results of this study suggest that TAF 401 showed lower activity and the TAF 355 fraction did not cause any toxicity against Vero cell lines tested. The in vitro infected models used for anti- $T$. gondii activity in this study are fundamental to anti-Toxoplasma drug research $[28,29]$ and worked well in this study. Vero cells were used for culturing $T$. gondii in vitro in this study. The addition of E. longifolia fractions to monolayers of Vero cells showed that they remained metabolically active and viable after infected with $T$. gondii. In our study, we confirmed that $T$. gondii could invade Vero cells and proliferate quickly. Our study demonstrated that TAF 355 effectively inhibited the growth of $T$. gondii, and was less toxic to Vero cells than Clindamycin. This finding signifies that TAF 355 might be potential candidate as an alternative to Clindamycin for the treatment of toxoplasmosis

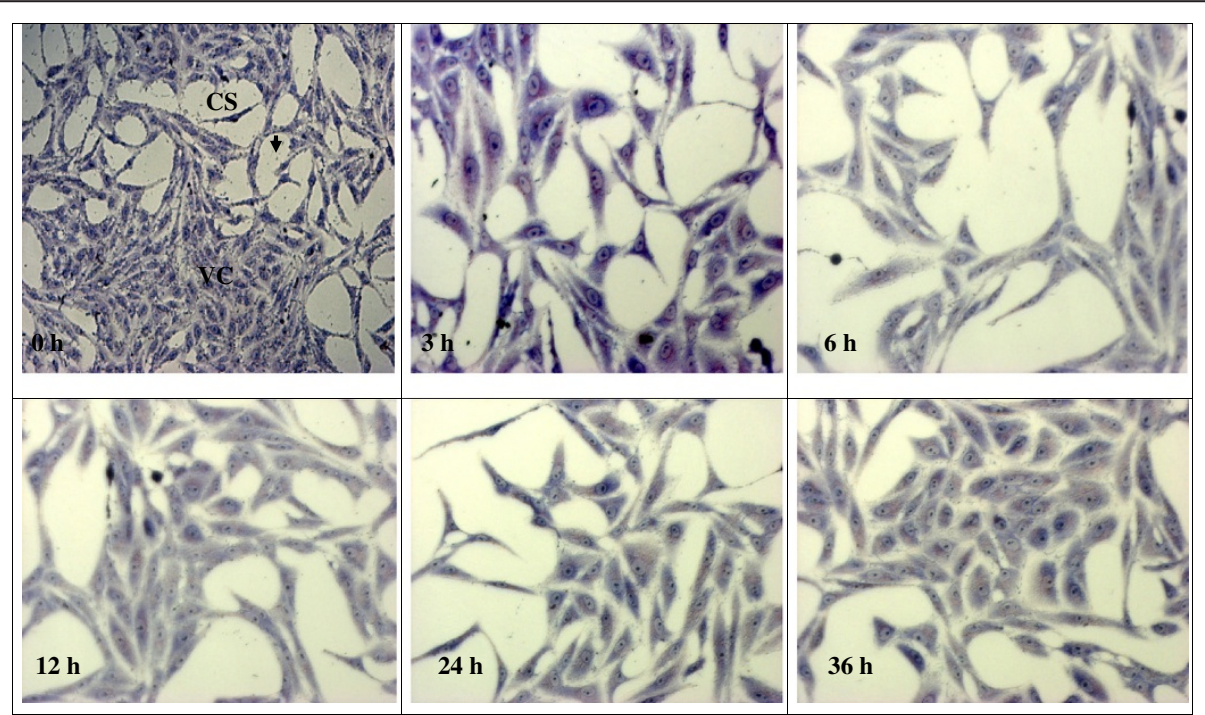

Figure 8 Morphology of Vero cells infected with $T$. gondii and TAF 401-treatment stained using Giemsa staining. The tachyzoites ( $\downarrow$ ) can be seen inside the Vero cells (VC), as well as adhered to the glass coverslip (CS). 
which deserves further study. Additionally to its toxicity, Clindamycin is expensive, limiting its availability to poor populations particularly living in the tropical and subtropical climates with low-income economies.

Similar results were also reported by Choi et al. [30]. They used 15 traditional herbs methanol extracts to evaluate the anti- $T$. gondii activity by using HeLa cells as host. The results show that the herbal extracts exhibited the best activity with the EC50 values ranged from $0.11 \mathrm{mg} / \mathrm{mL}$ to $2.28 \mathrm{mg} / \mathrm{mL}$. They also reported that Zingiber officinale extracts $(\mathrm{EC}(50)=0.18 \mathrm{mg} / \mathrm{mL})$, displayed the highest selective toxicity (selectivity $=10.1$ ) and Sophora flavescens Aiton extracts showed the highest anti- $T$. gondii activity $(\mathrm{EC}(50)=0.20 \mathrm{mg} / \mathrm{mL})$ with high selective toxicity.

Advances in microscopy technique to observed at ultrastructural level of cells morphology enhance the understanding of in situ antiparasitic activity observation. The microscopy method enables in situ observations of the effect of anti-parasitic agents on the organisms [31]. In this study light microscopy technique was used to observe the suppression of $T$. gondii growth by clindamycin, TAF 355 and TAF 401. The tachyzoites can be seen inside the Vero cells, as well as adhered to the glass coverslip. As predicted, the number of tachyzoites observed in the presence of clindamycin, TAF 355 and TAF 401 decreased in a time-dependent manner with increasing time of incubation in the medium with clindamycin. The morphology of Vero cells changed remarkably after the exposure to clindamycin, this exemplified the previous observations that commercial drugs may have severe side effects on the host cells [32]. Normally the rapidly proliferating $T$. gondii tachyzoites propagate by host cell lysis, egression, reattachment, and invasion of new host cells [33]. The remarkable changes observed in the morphology and confluence of Vero cells in 1\% DMSO treated group (negative control) is probably due to the above fact. However, TAF 355 and TAF 401 treatment did not remarkably affect the normal growth and morphology of the infected host cells despite the potent anti-T. gondii activities, the cells seemed to remain metabolically active and viable. In fact cells proliferation and confluence were higher than when exposed to clindamycin. This observation verified that E. longifolia fractions had high anti-T. gondii activity but had no selective toxicity against the infected host cells, particularly TAF 355 and TAF 401. Our results also indicate that the mechanism of action of TAF 355 and TAF 401 against T. gondii differs from its activity against the host cells. Based on the above results, TAF 355 may be better than clindamycin for the treatment of toxoplasmosis.

With regard to the mechanism of action for TAF 355 and TAF 401 against $T$. gondii, we hypothesize that TAF 355 and TAF 401 may produce intracellular oxidative stress by an indirect mechanism [34]. Existing drugs such as atovaquone inhibit apicomplexans such as Plasmodium falciparum through redox mechanisms [35]. In contrast, the TAF 355 and TAF 401 protected the Vero cells. The exact mechanism of action of TAF 355 and TAF 401 at the level of the host cell remains unknown. However, the favorable effect may be attributed to its anti-oxidant properties, which have been well documented in the previous studies [36,37]. Mitochondria are the largest source of reactive oxygen species (ROS) within cells [38]. Moreover, uncontrolled superoxide flashes in mitochondria contribute to global oxidative stress, playing a key role in hypoxia/reoxygenation injury in cells [39]. This model provides a rational explanation for why TAF 355 and TAF 401 inhibit T. gondii growth and protects the Vero cells by selective toxicity. To confirm this, we will investigate the mechanism of action of TAF 355 and TAF 401 in our future studies.

\section{Conclusions}

The search for anti-T. gondii agent from Malaysia medicinal plants has led to the finding that fractions of $E$. longifolia, in particular TAF 355, showed potent anti-T. gondii activity. These results, first reported in this work, have allowed us to propose that fractions from E. longifolia root are likely the sources of new compounds that could be used to treat $T$. gondii infections. Further studies will be necessary to identify, isolate and characterized these active compounds.

Competing interest

The authors declare that they have no competing interests.

Authors' contributions

NK, RN, KLC and SS developed and piloted the survey. NK, RN, and SS performed the analysis. NK, RN, KLC and SS wrote the manuscript. All authors have read and approved the final version of the manuscript.

\section{Acknowledgements}

This project was funded by Research University Grant (1001/CIPPM/813025) from Universiti Sains Malaysia. Nowroji Kavitha was supported by Universiti Sains Malaysia fellowship from Institute for Postgraduate Studies, Universiti Sains Malaysia.

\section{Author details}

${ }^{1}$ Institute for Research in Molecular Medicine (INFORMM), Universiti Sains Malaysia, 11800 USM, Pulau Pinang, Malaysia. ${ }^{2}$ School of Pharmaceutical Sciences, Universiti Sains Malaysia, USM 11800, Pulau Pinang, Malaysia.

Received: 10 February 2012 Accepted: 28 June 2012

Published: 10 July 2012

\section{References}

1. Sreenivasan S, Yoga Latha L: Time To Revisit Neglected Tropical Diseases In The New Viewpoint. Webmed Central Trop Med 2010, 1(9):WMC00517.

2. Luder CG, Bohne W, Soldati D: Toxoplasmosis: a persisting challenge. Trends Parasitol 2001, 17:460-463.

3. Kasper LH: Toxoplasma Infection. Columbus, OH, USA: McGraw-Hill Companies; 2002. Available: www.harrisonsonline.com.

4. McFadden Gl: Plastids and protein targeting. J Eukaryot Microbio/ 1999, 46:339-346.

5. Montoya JG, Liesenfeld O: Toxoplasmosis. Lancet 2004, 363:1965-1976. 
6. Butler D: Vaccine venture boosts health hopes. Nature 2009, 461:323-323.

7. Gimlette JD, Thomson HW: A Dictionary of Malayan Medicine. Kuala Lumpur, Malaysia: Oxford University Press; 1977:183.

8. Perry LM: Medicinal Plants for East and Southeast Asia. Attributed Properties and Uses. MA: M.I.T. Press; 1980:389.

9. Itokawa $\mathrm{H}$, Kishi $\mathrm{E}$, Morita $\mathrm{H}$, Takeya $\mathrm{K}$ : Cytotoxic quassinoids and tirucallane-type triterpenes from the woods of Eurycoma longifolia. Chem Pharm Bull 1992, 40:1053-1055.

10. Chan KL, O'Neill MJ, Phillipson JD, Warhurst DC: Plants as sources of antimalarial drugs. Part 3. Eurycoma longifolia Jack. Planta Med 1986, 52:105-107.

11. Chan $\mathrm{KL}$, Lee SP, Sam TW, Han BH: A quassinoid glycoside from the roots of Eurycoma longifolia. Phytochemistry 1989, 28:2857-2859.

12. Chan KL, Lee SP, Sam TW, Tan SC, Noguchi H, Sankawa U: 138,18 dihydroeurycomanol, a quassinoid from Eurycoma longifolia. Phytochemistry 1991, 30:3138-3141.

13. Ang HH, Chan KL, Mak JW: Effect of 7-day daily replacement of culture medium containing Eurycoma longifolia Jack constituents on the Malaysian Plasmodium falciparum isolates. J Ethnopharmacol 1995, 49:171-175.

14. Ang HH, Chan $\mathrm{KL}$, Wah Mak J: In vitro antimalarial activity of quassinoids from Eurycoma longifolia against Malaysian chloroquine-resistant Plasmodium falciparum isolates. Planta Med 1995, 61:177-178.

15. Kardono LBS, Angerhofer CK, Tsauri S, Padmawinata K, Pezzuto JM, Kinghorn AD: Cytotoxic and antimalarial constituents of the roots of Eurycoma longifolia. J Nat Prod 1991, 54:1360-1367.

16. Morita $H$, Kishi $E$, Takeya $K$, Itokawa $H$, litaka $Y$ : New quassinoids from the roots of Eurycoma longifolia. Chem Lett 1990, 5:749-752.

17. Itokawa H, Kishi E, Morita H, Takeya K: Cytotoxic quassinoids and tirucallane-type triterpenes from the woods of Eurycoma longifolia. Chem Pharm Bul 1992, 40:1053-1055.

18. Itokawa H, Qin XR, Morita H, Takeya K, litaka Y: Novel quassinoids from Eurycoma longifolia. Chem Pharm Bul 1993, 41:403-405.

19. Chan KL, Choo CY, Noor RA, Zakiah I: Antiplasmodial studies of Eurycoma longifolia Jack using the lactate dehydrogenase assay of Plasmodium falciparum. J Ethnopharmacol 2004, 92:223-227.

20. Kavitha N, Noordin R, Chan KL, Sasidharan S: Cytotoxicity activity of root extract/fractions of Eurycoma longifolia Jack root against vero and Hs27cells. J Med Plants Res 2010, 4:2383-2387.

21. Cover B, Gutteridge WE: A primary screen for drugs to prevent transmission of Chagas's disease during blood transfusion. Trans $R$ SoC Trop Med Hyg 1982, 76:633-635.

22. Sheng-Xia C, Liang W, Xu-Gan J, Yao-Yu F, Jian-Ping C: Anti-Toxoplasma gondii activity of GAS in vitro. J Ethnopharmacol 2008, 118:503-507.

23. Rezai HR, Sher S, Gettner S: Leishmania tropica, L. donovani and L. enriettii: immune rabbit serum inhibitory in vitro. Exp Parasitol 1969, 26:257-263.

24. Belloni A, Villena I, Gomez JE, Pelloux H, Bonhomme A, Guenounou M, Pinon JM, Aubert D: Regulation of tumor necrosis factor alpha and its specific receptors during Toxoplasma gondii infection in human monocytic cells. Parasitol Res 2003, 89:207-213.

25. Williams C, Espinosa OA, Montenegro H, Cubilla L, Capson TL, Ortega-Barría E, Romero LI: Hydrosoluble formazan XTT: its application to natural products drug discovery for Leishmania. J Microbiol Methods 2003, 55:813816.

26. Park H, Kim MS, Jeon BH, Kim TK, Kim YM, Ahnn J, Kwon DY, Takaya Y, Wataya Y, Kimm HS: Antimalarial activity of herbal extracts used in traditional medicine in Korea. Biol Pharm Bull 2003, 26:1623-1624.

27. Renslo AR, McKerrow JH: Drug discovery and development for neglected parasitic diseases. Nat Chem Biol 2006, 2:701-710.

28. Fichera ME, Roos DS: A plastid organelle as a drug target in apicomplexan parasites. Nature 1997, 390:407-409.

29. Roos DS, Donald RGK, Mourrissette NS, Moulton ALC: Molecular tools for genetic dissection of the protozoan parasite Toxoplasma gondii. Methods Cell Biol 1994, 45:27-63.

30. Choi KM, Gang J, Yun J: Anti-Toxoplasma gondii RH strain activity of herbal extracts used in traditional medicine. Int J Antimicrob Agents 2008, 32:360-362.

31. Sasidharan S, Yoga Latha L, Angeline T, Méndez-Vilas A, Díaz J: Imaging In vitro anti-biofilm activity to visualize the ultrastructural changes. In Microscopy: Science, Technology, Applications and Education. Badajoz, Spain: Formatex 2010, 622:622-626.
32. Haverkos HW: Toxoplasmic encephalitis study group. Assessment of therapy for toxoplasmic encephalitis. Am J Med 1987, 82:907-914.

33. Strobl JS, Seibert CW, Li Y, Nagarkatti R, Mitchell SM, Rosypal AC, Rathore D, Lindsay DS: Inhibition of Toxoplasma gondii and plasmodium falciparum infections in vitro by NSC3852, a redox active antiproliferative and tumor cell differentiation agent. J Parasitol 2009, 95:215-223.

34. Strobl JS, Cassell M, Mitchell SM, Reilly CM, Lindsay DS: Scriptaid and suberoylanilide hydroxamic acid are histone deacetylase inhibitors with potent anti-Toxoplasma gondii activity in vitro. J Parasitol 2007, 93:694-700.

35. Baggish AL, Hill DR: Anti-parasitic agent atovaquone. Antimicrob Agents Chemother 2002, 46:1163-1173.

36. Tambi MI: Glycoprotein water-soluble extract of Eurycoma Longifolia Jack as a health supplement in management of Health aging in aged men. In Aging Male. Edited by Lunenfeld B. Berlin, Germany: Abstracts of the 3rd World Congress on the Aging Male; 2002:6.

37. Purwantiningsih, Hussin $\mathrm{AH}$, Chan $\mathrm{KL}$ : Free radical scavenging activity of the standardized ethanolic extract of Eurycoma longifolia (TAF-273). Int J Pharm Pharm Sci 2011, 3:343-347.

38. Balaban RS, Nemoto S, Finkel T: Mitochondria, oxidants and ageing. Cell 2005, 120:483-495

39. Wang W, Fang H, Groom L, Cheng A, Zhang W, Liu J, Wang X, Li K, Han P, Zheng M, Yin J, Wang W, Mattson MP, Kao JP, Lakatta EG, Sheu SS, Ouyang $\mathrm{K}$, Chen J, Dirksen RT, Cheng H: Superoxide flashes in single mitochondria. Cell 2008, 134:279-290.

doi:10.1186/1472-6882-12-91

Cite this article as: Kavitha et al.: In vitro Anti-Toxoplasma gondii Activity of Root Extract/Fractions of Eurycoma longifolia Jack. BMC Complementary and Alternative Medicine 2012 12:91.

\section{Submit your next manuscript to BioMed Central and take full advantage of:}

- Convenient online submission

- Thorough peer review

- No space constraints or color figure charges

- Immediate publication on acceptance

- Inclusion in PubMed, CAS, Scopus and Google Scholar

- Research which is freely available for redistribution

Submit your manuscript at www.biomedcentral.com/submit
C Biomed Central 